\title{
SUPERMATRIX AND SIMULATION IN BIDDING MODELS
}

\author{
Natalino Dazzi \\ Fisia Italimpianti \\ Via de Marini 16, 16149 Genoa (Italy) \\ natalino_dazzi@ffisiait.com \\ Giovanni Guglielmone \\ Department of Production Engineering, \\ University of Genoa, \\ via all’Opera Pia 15, 16145- Genoa (Italy) \\ guglielmone@dip.unige.it
}

Keywords: ANP Supermatrix, Montecarcarlo Simulation, Tender Proposal

Summary: A framework based on ANP supermatrix and Montecarlo simulation to be used by a bidding firm, is presented. The supermatrix allows a detailed representation of the bidding firm position versus the other competitors with respect to critical factors.

\section{Introduction}

In tenders of supplies or works the assessment procedure based on several weighed criteria is usual. In this procedure, the price is only a criterion among the other ones - and often not the most important one. Therefore the correct choice of the best supplier becomes very difficult. Decision theory models could support the choice and give more robust solutions, but are not yet a standard tool in use for Judgement Committees. In most cases, the Committees are not quite aware of the risk being inside the decision problems. In this way, formulation and process of simple models lead to inconsistent solutions. Really, in public choices matter the paradoxes are frequent.

The bidders are anyway able to build their decision support model using certain information and uncertain hypotheses. Today many software tools are available to process stochastic models and to perform lowcost, user friendly simulations.

Supermatrix of Analytic Network Priority (ANP) [1] allows elicitation of a judgement which is quite close to the prebidding situation, as is in the mind of the manager. By first, his own company and the other ones are to be evaluated with respect to each criterion relevant for the tender. The other part of the input allows the manager to express his valuations about the criteria, simulating perfectly consistent judgements of Committee. Actually, both his own company as well as the other competitors will be evaluated by the Committee according to these criteria. The two input parts of supermatrix allow the manager to express his personal vision about his own tender, the expected tenders from competitors, the correct weights of criteria (within the ordinal list given in official tender).

In order to model the variability of the judgements, pairwise comparison values are considered as probabilistic values under given distributions. By running a simulation [2] it is possible to obtain a probabilistic solution of supermatrix. This result gives a first indication about the company's strength in the present tender and a support in order to improve, if necessary, the valuation (either by acquiring new information over competitors or by changing some features of company's bid). By using an optimizing stochastic tool it is also possible to find the price maximizing the expected economic result. 


\section{ANP Supermatrix}

The case of a bid for a large plant, what has to be realised under a Project Financing scheme, is considered as reference example. The plant could be a set of units for integrated management of urban solid waste at metropolitan area level. The basic components usually include an incineration unit and a unit converting the thermal energy developed in the combustion phase into electrical power.

The proposal usually contains a set of criteria which are to be used in order to select the winner within the applicant suppliers. The more common criteria used in such a situation are price, project technical evaluation, contractor experience.

A supplier facing with such a proposal has usually information about competitors which are going to apply for the same proposal. The quality of his knowledge is quite detailed for well known competitors, because it was acquired through a lengthy activity in the specific industrial sector. There is a poorer quality of knowledge about other competitors, which are the newcomers into the area.

This kind of different qualities of knowledge is clearly addressed in the present paper and is represented using range values in pairwise comparison matrices. These matrices are used to derive the proper values for the supermatrix.

The format of the ANP Supermatrix is portrayed in the following table.

\begin{tabular}{|l|l|l|l|l|l|l|}
\hline Price & $\begin{array}{c}\text { Project } \\
\text { Technical } \\
\text { Evaluation }\end{array}$ & $\begin{array}{c}\text { Contractor } \\
\text { Experience }\end{array}$ & $\begin{array}{c}\text { Own Firm } \\
\text { Bid }\end{array}$ & $\begin{array}{c}\text { Well Known } \\
\text { Competitor }\end{array}$ & $\begin{array}{c}\text { Recent } \\
\text { Competitor }\end{array}$ \\
\hline Price & & & & & & \\
\hline $\begin{array}{l}\text { Project } \\
\text { Evaluation }\end{array}$ & & & & & & \\
\hline $\begin{array}{l}\text { Contractor } \\
\text { Experience }\end{array}$ & & & & & & \\
\hline $\begin{array}{l}\text { Own Firm } \\
\text { Bid }\end{array}$ & & & & & & \\
\hline $\begin{array}{l}\text { Well Known } \\
\text { Competitor }\end{array}$ & & & & & & \\
\hline $\begin{array}{l}\text { Recent } \\
\text { Competitor }\end{array}$ & & & & & & \\
\hline
\end{tabular}

Table 1 Supermatrix

In order to evaluate the shaded area in the left-bottom part of supermatrix (table 1) three pairwise comparison matrices have to be evaluated (Table 2,3,4):

\begin{tabular}{|l|c|c|c|}
\hline Price & Own Firm Bid & $\begin{array}{c}\text { Well Known } \\
\text { Competitor }\end{array}$ & Recent Competitor \\
\hline Own Firm Bid & 1 & $\mathrm{a}_{12}$ inf- $\mathrm{a}_{12}$ sup & $\mathrm{a}_{13}$ inf- $\mathrm{a}_{13}$ sup \\
\hline $\begin{array}{l}\text { Well Known } \\
\text { Competitor }\end{array}$ & & 1 & $\mathrm{a}_{23}$ inf- $\mathrm{a}_{23}$ sup \\
\hline Recent Competitor & & & 1 \\
\hline
\end{tabular}


Table 2 Pairwise comparison matrix with respect to Price

\begin{tabular}{|l|c|c|c|}
\hline $\begin{array}{l}\text { Project Technical } \\
\text { Evaluation }\end{array}$ & Own Firm Bid & $\begin{array}{l}\text { Well Known } \\
\text { Competitor }\end{array}$ & Recent Competitor \\
\hline Own Firm Bid & 1 & $\mathrm{~b}_{12}$ inf- $\mathrm{b}_{12}$ sup & $\mathrm{b}_{13}$ inf- $\mathrm{b}_{13}$ sup \\
\hline $\begin{array}{l}\text { Well Known } \\
\text { Competitor }\end{array}$ & & 1 & $\mathrm{~b}_{23}$ inf- $\mathrm{b}_{23}$ sup \\
\hline Recent Competitor & & & 1 \\
\hline
\end{tabular}

Table 3 Pairwise comparison matrix with respect to Project Technical Evaluation

\begin{tabular}{|l|c|c|c|}
\hline $\begin{array}{l}\text { Contractor } \\
\text { Experience }\end{array}$ & Own Firm Bid & $\begin{array}{l}\text { Well Known } \\
\text { Competitor }\end{array}$ & Recent Competitor \\
\hline Own Firm Bid & 1 & $\mathrm{c}_{12}$ inf- $\mathrm{c}_{12}$ sup & $\mathrm{c}_{13}$ inf- $\mathrm{c}_{13}$ sup \\
\hline $\begin{array}{l}\text { Well Known } \\
\text { Competitor }\end{array}$ & & 1 & $\mathrm{c}_{23}$ inf- $\mathrm{c}_{23}$ sup \\
\hline Recent Competitor & & & 1 \\
\hline
\end{tabular}

Table 4 Pairwise comparison matrix with respect to Contractor Experience

In the active cells of the pairwise comparison matrices (tables, 2,3,4) are indicated range values.

Decision makers are unable, due to their imperfect knowledge, to express single values. Their judgement will be confined within an interval, reasonably narrow when a well known competitor is involved, wider when a newcomer is considered.

It seem unrealistic to assume that the probabilistic distributions for each range value are independent not only within the same matrix but also with respect to the set of the three above defined pairwise comparison matrices. The first problem addressed by the present paper is then related to work out a sort of correlation between variables of the above-defined matrices.

By first, the pairwise comparison data related to the judgement between Our Firm Bid and the Well Known Competitor are considered (all the cells with indices 12). Decision makers express their judgements for the active cells of the above defined matrices as range values. Two values (inf and sup) are indicated for each active cell. Through a simulation technique, values in accordance with a predefined probalistic distribution will be sampled for each cell. The sampled values are named $a_{12}, b_{12}, c_{12}$.

It seem reasonable to assume as independent variable the one related to the pairwise comparison with respect to Contractor Experience criterion, because the past experience within specific industrial sector represents the first and widest spread of knowledge. This means that the values $a_{12}, b_{12}$, are correlated with $\mathrm{c}_{12}$. This correlation would be positive for $\mathrm{b}_{12}$ and negative for $\mathrm{a}_{12}$.

The correlation is expressed using an indirect approach. An uniform distribution function is assumed for the variable $c_{12}$ (limited by the extreme values $c_{12}$ inf e $c_{12}$ sup). A triangular distribution function is assumed for the variable $a_{12}$ and variable $b_{12}$.

In order to express the correlation between $\mathrm{c}_{12}$ and $\mathrm{a}_{12}, \mathrm{~b}_{12}$, a very simple model is used. Let $\mathrm{c}_{\mathrm{s} 12}$ be the sampled value in the Montecarlo simulation, the values for variables $a_{12}, b_{12}$ (that is $a_{s 12}, b_{s 12}$, respectively) are sampled out from the following triangular distributions: 

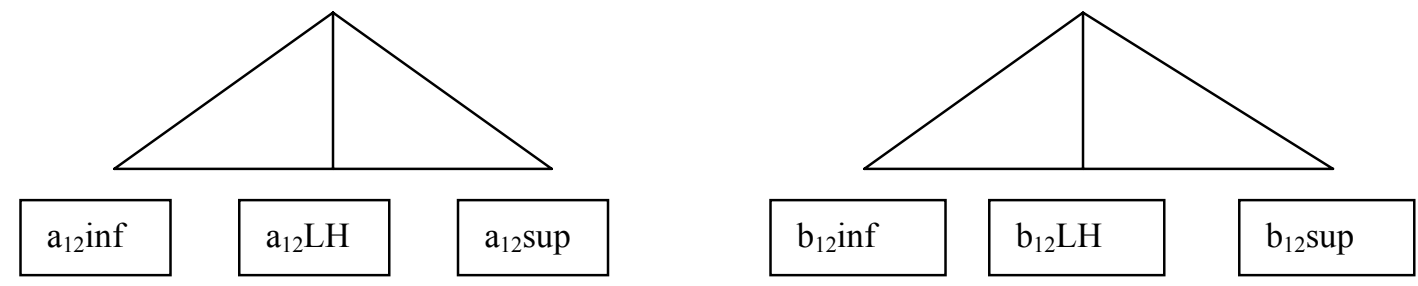

where the likelihood values are calculated as

$$
\begin{aligned}
& \mathrm{a}_{12} \mathrm{LH}=\mathrm{a}_{12} \text { inf }+\left[\left(\mathrm{c}_{12} \text { sup- } \mathrm{c}_{\mathrm{s} 12}\right) /\left(\mathrm{c}_{12} \text { sup-c } \mathrm{c}_{12} \text { inf }\right)\right] *\left[\mathrm{a}_{12} \text { sup-a } \mathrm{a}_{12} \text { inf }\right] \\
& \mathrm{b}_{12} \mathrm{LH}=\mathrm{b}_{12} \text { inf }+\left[\left(\mathrm{c}_{\mathrm{s} 12}-\mathrm{c}_{12} \text { inf }\right) /\left(\mathrm{c}_{12} \text { sup-c } \mathrm{c}_{12} \text { inf }\right)\right] *\left[\mathrm{~b}_{12} \text { sup- } \mathrm{b}_{12} \text { inf }\right]
\end{aligned}
$$

The same considerations apply also for the pairwise comparison values related to the judgement between Own Firm Bid and Recent Competitor, although the judgements expressed by the manager will be in a wider range.

The following sheet shows an abstract of calculation process.

Gross borded cells contain probability distribution functions, whose parameters are given in the right side of the sheet. Price and Project Technical Evaluation have triangular distributions, as above said, while Contractor Experience (i.e. pilot variable) has uniform distribution. All input values are shown in bold style.

A perfect consistency of decision maker is assumed, so that $\mathrm{c}_{12}$ type coefficients are derived from other input coefficients.

In our example probabilistic functions are assigned only to criteria. No uncertainty affects the alternatives, i.e. the upper-right side of supermatrix (see Table1) is not probabilistic.

At the bottom of sheet the initial and final values of supermatrix are shown. The convergence in final values of the supermatrix was obtained by elevating the initial supermatrix at the eighth power.

Finally, the last row reports the winner competitor. 
PRICE

$\begin{array}{rrrrrr} & \mathrm{a} & \mathrm{b} & \mathrm{c} & & \\ \mathrm{a} & \mathbf{1 , 0} & 2,0 & 0,8 & 3,8 & 0,35 \\ \mathrm{~b} & 0,5 & \mathbf{1 , 0} & 0,4 & 1,9 & 0,18 \\ \mathrm{c} & 1,3 & 2,7 & \mathbf{1 , 0} & 5,0 & 0,47 \\ & & & & 10,6 & 1,00\end{array}$

INPUT DISTRIBUTIONS PARAMETERS

$\begin{array}{llllll}b_{\text {inf }} & b_{\text {LH }} & b_{\text {sup }} & c_{\text {inf }} & c_{\text {LH }} & c_{\text {sup }}\end{array}$

$\begin{array}{llllll}\mathbf{1 , 0} & 2,0 & \mathbf{3 , 0} & \mathbf{0 , 5} & 0,8 & \mathbf{1 , 0}\end{array}$

$\begin{array}{llllll}b_{\text {inf }} & b_{\text {LH }} & b_{\text {sup }} & c_{\text {inf }} & c_{L H} & c_{\text {sup }}\end{array}$

$\begin{array}{llllll}\mathbf{0}, 3 & 0,7 & \mathbf{1 , 0} & \mathbf{1 , 0} & 1,5 & \mathbf{2 , 0}\end{array}$

CONTRACTOR EXPERIENCE (Pilot variable)

\begin{tabular}{cccccc}
\multicolumn{7}{c}{} & $\mathrm{a}$ & $\mathrm{b}$ & $\mathrm{c}$ & & \\
$\mathrm{a}$ & $\mathbf{1 , 0}$ & 0,8 & $\mathbf{1 , 5}$ & 3,3 & 0,33 \\
$\mathrm{~b}$ & 1,3 & $\mathbf{1 , 0}$ & $\mathbf{2 , 0}$ & 4,3 & 0,44 \\
$\mathrm{c}$ & 0,7 & 0,5 & $\mathbf{1 , 0}$ & 2,2 & 0,22 \\
& & & & 9,8 & 1,00
\end{tabular}

$\begin{array}{ccccc}b_{\text {inf }} & b_{\text {sup }} & c_{\text {inf }} & c_{\text {sup }} \\ 0,5 & 1,0 & 1,0 & 2,0\end{array}$

Alternative a: OWN FIRM BID

Price Techn.Eval. Contr.Exp.

\begin{tabular}{lll|rrr|} 
Price & $\mathbf{1 , 0}$ & $\mathbf{1 , 0}$ & $\mathbf{2 , 0}$ & 4,0 & 0,40 \\
Techn.Eval. & 1,0 & $\mathbf{1 , 0}$ & $\mathbf{2 , 0}$ & 4,0 & 0,40 \\
Contr.Exp. & 0,5 & 0,5 & $\mathbf{1 , 0}$ & 2,0 & 0,20 \\
\hline & & & & 10,0 & 1,00
\end{tabular}

Alternative b: WELL KNOWN COMPETITOR

Price Techn.Eval. Contr.Exp.

\begin{tabular}{lrrrrr} 
Price & $\mathbf{1 , 0}$ & $\mathbf{0 , 5}$ & $\mathbf{0 , 3}$ & 1,8 & 0,16 \\
Techn.Eval. & 2,0 & $\mathbf{1 , 0}$ & 0,6 & 3,6 & 0,32 \\
Contr.Exp. & 3,3 & 1,7 & $\mathbf{1 , 0}$ & 6,0 & 0,53 \\
\hline
\end{tabular}

Alternative c: RECENT COMPETITOR

Price Techn.Eval. Contr.Exp.

$\begin{array}{lrrrrr}\text { Price } & \mathbf{1 , 0} & \mathbf{3 , 0} & \mathbf{3 , 0} & 7,0 & 0,60 \\ \text { Techn.Eval. } & 0,3 & \mathbf{1 , 0} & 1,0 & 2,3 & 0,20 \\ \text { Contr.Exp. } & 0,3 & 1,0 & \mathbf{1 , 0} & 2,3 & 0,20 \\ & & & & 11,7 & 1,00\end{array}$

SUPERMATRIX (initial values)

\begin{tabular}{l|r|r|r|r|r|r|}
\multicolumn{1}{c}{} & \multicolumn{2}{c}{ Price Techn.Eval. Contr.Exp. } & \multicolumn{1}{c}{ a } & \multicolumn{1}{c}{ b } \\
\cline { 2 - 7 } Price & 0,00 & 0,00 & 0,00 & 0,40 & 0,16 & 0,60 \\
\cline { 2 - 7 } Techn.Eval. & 0,00 & 0,00 & 0,00 & 0,40 & 0,32 & 0,20 \\
\cline { 2 - 7 } Contr.Exp. & 0,00 & 0,00 & 0,00 & 0,20 & 0,53 & 0,20 \\
\cline { 2 - 7 } a & 0,35 & 0,32 & 0,33 & 0,00 & 0,00 & 0,00 \\
b & 0,18 & 0,47 & 0,44 & 0,00 & 0,00 & 0,00 \\
\cline { 2 - 7 } c & 0,47 & 0,21 & 0,22 & 0,00 & 0,00 & 0,00 \\
\cline { 2 - 7 }
\end{tabular}

SUPERMATRIX (final values)

\begin{tabular}{|c|c|c|c|c|c|c|}
\hline & Price & Techn.Eval. & Contr.Exp. & a & $b$ & $\mathrm{C}$ \\
\hline \multirow{3}{*}{$\begin{array}{l}\text { Price } \\
\text { Techn.Eval. } \\
\text { Contr.Exp. }\end{array}$} & 0,00 & \begin{tabular}{|r|}
0,00 \\
\end{tabular} & 0,00 & 0,38 & 0,38 & 0,38 \\
\hline & 0,00 & 0,00 & 0,00 & 0,31 & 0,31 & 0,31 \\
\hline & 0,00 & 0,00 & 0,00 & 0,31 & 0,32 & 0,31 \\
\hline a & 0,34 & 0,34 & 0,34 & 0,00 & 0,00 & 0,00 \\
\hline b & 0,35 & 0,35 & 0,35 & 0,00 & 0,00 & 0,00 \\
\hline c & 0,31 & 0,31 & 0,31 & 0,00 & 0,00 & 0,00 \\
\hline
\end{tabular}

SUPERMATRIX MAX $\quad 0,35$

WINNER COMPETITOR: b 
The following figure shows the output distribution of different winners. In our example, about $13 \%, 80 \%$ and $7 \%$ are the probabilities of winning for $a, b$, c competitor, respectively.. Optimization analyses (here not included) are also possible in order to define the best price value reaching a given probability value and the maximum value of expected return.

\section{Distribution for WINNER COMPETITOR: / \\ $\mathrm{b} / \mathrm{C69}$}

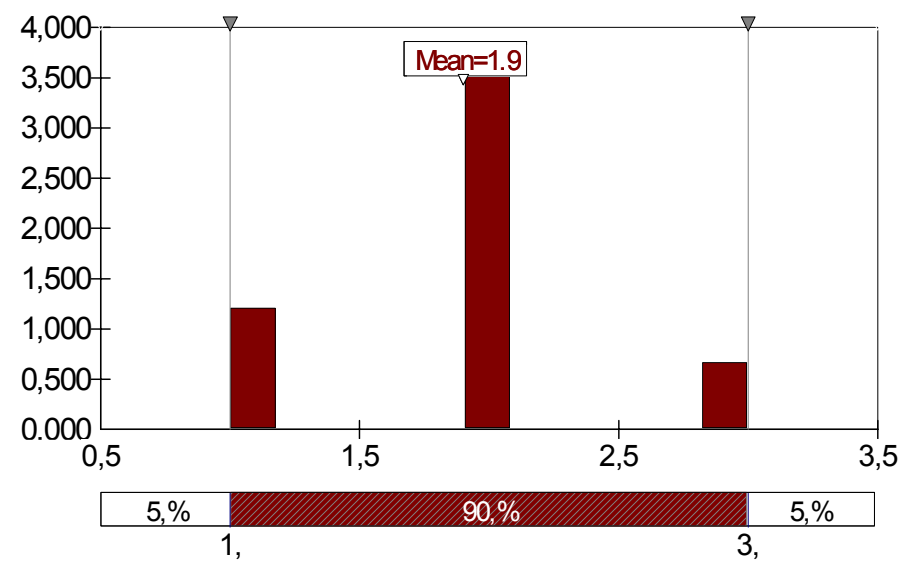

\section{Conclusion}

The use of supermatrix seems very suitable to allow decision makers to express their judgements about points of strength and weakness of their firm with relation to other competitors in a bidding situation. The bottom left part of the supermatrix allows the comparison of the competitors with respect to each relevant factor. The upper right portion of the supermatrix allows the representation of the priority of relevant factors for each firm.

The use of interval values for pairwise comparison judgements, the assignment of probability distribution function and the use of Montecarlo simulation give a lot of flexibility to the whole process.

\section{Reference}

1] T.L. Saaty, The Analytic Network Process, RWS publication, Pittsburgh 1996

2] Guide to using@Risk, Risk analysis and simulation, add-in for Microsoft Excel, Palisade corporation, Newfield, NY 2000 